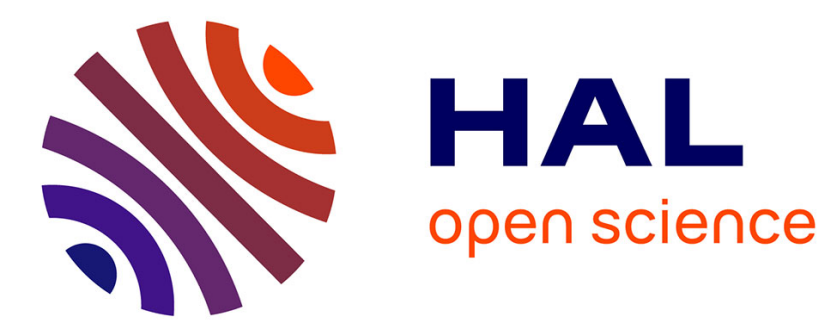

\title{
Primary knowledge enhances performance and motivation in reasoning.
}

Florence Lespiau, André Tricot

\section{To cite this version:}

Florence Lespiau, André Tricot. Primary knowledge enhances performance and motivation in reasoning.. Learning and Instruction, 2018, 56, pp.10-19. 10.1016/j.learninstruc.2018.02.007 . hal01736920

\section{HAL Id: hal-01736920 \\ https://hal.science/hal-01736920}

Submitted on 17 Jul 2019

HAL is a multi-disciplinary open access archive for the deposit and dissemination of scientific research documents, whether they are published or not. The documents may come from teaching and research institutions in France or abroad, or from public or private research centers.
L'archive ouverte pluridisciplinaire HAL, est destinée au dépôt et à la diffusion de documents scientifiques de niveau recherche, publiés ou non, émanant des établissements d'enseignement et de recherche français ou étrangers, des laboratoires publics ou privés. 


\section{Primary knowledge enhances performance and motivation in reasoning}

Florence Lespiau and André Tricot

CLLE-LTC - Cognition, Langues, Langage, Ergonomie

CNRS and University of Toulouse

Toulouse, France

NOTICE: this is the author's version of a work that was accepted for publication in Learning and Instruction. Changes resulting from the publishing process, such as peer review, editing, corrections, structural formatting, and other quality control mechanisms may not be reflected in this document. Changes may have been made to this work since it was submitted for publication. A definitive version was subsequently published in Learning and Instruction, [Lespiau, F. \& Tricot, A. (2018). Primary knowledge enhances performance and motivation in reasoning. Learning and Instruction, 56, 10-19. doi: 10.1016/j.learninstruc.2018.02.007].

Correspondance: Florence Lespiau florence.lespiau@ gmail.com 


\section{Introduction}

\subsection{Issues in learning normative logic as secondary knowledge}

Learning at school demands conscious efforts, motivation (often extrinsic) and time. The main aim of formal education is to teach culturally important knowledge which would be very difficult to learn by oneself or by simple social interactions (Sweller, 2015). Students are asked to apply rules in a logical way which may be different from the kind of logic they are using every day (Stanovich \& West, 2000). They must be able to implement a strict specific grammar rule, to demonstrate a mathematical theorem, to solve physics equations, to apply scientific reasoning and so on. Despite logic being omnipresent, it is not necessarily taught as such and the context of its learning is neglected: for example, in Johnson-Laird's 573 pages book "How we reason" (2006), there is nothing about learning to reason. One issue is that logical problems are not engaging first:

\section{If $A$, then $B$.}

$B$.

$A$ ?

When they are faced with that kind of problem, students tend to sense a trap in the question leading them to disengage from the task (Evans, 2005; De Neys \& Feremans, 2013; Johnson, Tubau \& De Neys, 2016). The logical reasoning expected from high schools to universities is indeed a complex field to master. It is rather intriguing that so few people consider its learning: many works are concerned with computer programing (Barker-Plummer, Barwise \& Etchemendy, 2008) or medical reasoning (Barrows, 1994), but very few deal with a comprehensive learning of logic that could be of interest to people from all walks of life. A hundred years ago, we were already intrigued by the difficulty to teach and to learn logic (Carroll, 1896).

Learning is a complicated process and several approaches seek to find ways to facilitate it. For example, the cognitive load theory specifies that the cognitive load should not exceed working memory capacity (Paas, Renkl \& Sweller, 2003; Sweller, Ayres \& Kalyuga, 2011). Nevertheless, according to the desirable difficulties theory, this cognitive load should be sufficient enough to promote learners' engagement as much, if not more, than the learners' performances (Bjork \& Bjork, 2011; Chi \& Wylie, 2014). The present research provides a novel idea that could be used in the design of educational materials. But learning skills also come from the individuals' intentions. 
Because learning academic knowledge is a long and difficult process, it requires motivation (Ellis, 2008). But whatever the field of learning, even when learners are motivated to learn, it is not uncommon for them to get demotivated along the way and to give up learning. The main concern of teachers and parents is therefore to foster motivation, pleasure in learning and engagement in learning tasks (Braver et al., 2014; Cosnefroy, Nurra \& Dessus, 2016). Given the importance of logic (mostly abstract logic) in our current societies (Markovits \& Lortie-Forgues, 2011) and the difficulties in engaging learners durably in learning, it is essential to investigate which factors influence this emotional and cognitive engagement.

\subsection{Reasoning with conditionals contents}

Logical problems can take different forms (De Neys \& Bonnefon, 2013). Conditional rules and their inferences can be considered as syllogisms. Conditional problems as "if A, then B" imply four inference types: Modus Ponens (MP) “A. B?”, Modus Tollens (MT) “No B. A?”, Affirmation of the Consequent (AC) “B. A?" and Denial of the Antecedent (DA) "No A. B?". According to the logical norms, $M P$ and $M T$ are valid inferences where $M P$ is true and $M T$ is false whereas AC and DA are invalid inferences where the answer cannot be given with certainty. Almost everyone can solve $M P$, the majority of individuals solves $M T$, but even less succeed AC and DA (little resistance to invalid inferences) (De Neys, Schaeken \& d'Ydewalle, 2005; Evans, Handley, Neilens \& Over, 2007; Newstead, Handley, Harley, Wright \& Farrelly, 2004).

It is well-known that logical problems' content influences individuals' responses. If the problem is abstract, i.e. it does not represent anything realistic (particularly, involving letters or numbers; Evans et al., 2007), the reasoning process is more difficult. Thus, one is inclined to answer "yes" to the example "if A, then B; B. A?", thinking that the link between A and B is bidirectional (Dominowski, 1995; Evans, Handley, \& Bacon, 2009). If the example above is presented in more concrete terms such as:

If someone wants to find the length of a right triangle's side, then he uses the Pythagoras theorem.

Jack uses the Pythagoras theorem.

Does that mean he wants to find the length of a right triangle's side?

The reasoning process is then easier (Dominowski, 1995). Indeed, one can imagine other reasons why Jack would use the Pythagoras theorem: he may want to prove that a triangle is a right triangle 
or not. It thus invalidates the necessity of the antecedent through counter-examples (De Neys \& Everaerts, 2008; De Neys et al., 2005). The effect of logical problems' content and the importance of prior knowledge about the problem's context can lead to higher performances (deontic tasks, Cosmides \& Tooby, 2004; Evans, 2005; Markovits, 1986; the increase of counter-examples or more complete mental models, Johnson-Laird, 2005) or to completely bias individuals' responses (De Neys, 2006; De Neys \& Feremans 2013; Evans, 2005; Handley, Newstead \& Trippas 2011; Morsanyi \& Handley, 2012). This bias effect can be explained by the dual models approach (Evans, 2009; Stanovitch \& West, 2000) when the heuristic, automatic, rapid and cheaper in cognitive resources responses of system 1 conflict with the analytical, conscious, slow and very expensive in cognitive resources responses of system 2. Such conflict detection is then necessary for the system 2 to inhibit the system 1 response and then to generate its own response (De Neys \& Bonnefon, 2013). System 1 is considered universal, supporting survival whereas system 2 is more personal utility directed (Stanovitch \& West, 2000). Numerous studies also showed that adding a cognitive load, with a Dot Memory Task for example (De Neys, 2006; Trémolière, Gagnon \& Blanchette, 2017), increases the number of heuristic responses in logical problems: the cognitive resources in working memory are used to process the added cognitive load and thus are less available to reason consciously. The number of heuristic responses can be reduced if the capacity of working memory is significant (De Neys, 2006; Newstead et al., 2004; Stanovitch \& West, 2000). However, the respective implications of the two systems are not clear when it comes to conditionals (Bonnefon, Eid, Vautier \& Jmel, 2008). Literature is extremely extensive about logical problems' content, but no research, as far as we know, has linked logical reasoning with the evolutionary approach about knowledge learning.

\subsection{What type of knowledge we acquire inside and outside schools and how we acquire it}

We do not reason in the same way in everyday life and in schools. Our reasoning in everyday life is to be effective in a limited time with incomplete and doubtful information (heuristics) (Morsanyi \& Handley, 2008). These strategies are far different from those that must be used in schools, logic requiring more conscious thought, efforts and time (analytical). The strategies used in everyday life are more linked to biologically primary knowledge whereas other strategies are linked to biologically secondary knowledge. The classical normative logic is secondary knowledge because we did not evolve to be logical (Stanovich, West \& Toplak, 2011), we learn to be effective most of the time (Geary \& Bjorklund, 2000). According to a recent theory in evolutionary educational psychology (Geary, 2007, 2008, 2012; Geary \& Berch, 2015, 2016), human beings evolved 
specifically to acquire primary knowledge distributed in folk psychology (e.g., self-awareness, face recognition, facial expressions, language, group dynamics, theory of mind), folk biology (e.g., fauna, flora, food) and folk physics (e.g., navigation). This acquisition is easy, unconscious and fast contrary to secondary knowledge (e.g., mathematics, grammar, every academic disciplines) for which our brain did not have enough time to evolve. The ease of acquisition of primary knowledge is linked to their essential function in the survival of our species: for example, it is directly useful to be able to recognize kin or to be able to spot the best food (Kaplan, Hill, Lancaster \& Hurtado, 2000). Primary knowledge is generalizable whereas secondary knowledge is very difficult to generalize and is rather specific (Tricot \& Sweller, 2014). Additionally, individuals are intrinsically motivated to engage in task that involve primary knowledge acquisition while extrinsic motivation is often required to learn secondary knowledge (Geary \& Berch, 2016).

The recent massive accumulation of secondary knowledge made schools indispensable for individuals to be adapted regarding our societies' demands which are not the same as those of our ancestors' (Richerson \& Boyd, 2005). The motivational feature of primary knowledge is therefore an essential asset to be promoted in learning. Moreover, secondary knowledge is built on primary knowledge. For example, learning to read (secondary knowledge) is based on sound segmentation (primary knowledge). Primary knowledge facilitates the acquisition of secondary knowledge, particularly through the use of primary mechanisms that increase working memory capacity and reduce the impact of cognitive load promoting learning (Glenberg, Goldberg \& Zhu, 2011; Kirschner, Paas \& Kirschner, 2011; Paas \& Ayres, 2014; Paas \& Sweller, 2012; Ping \& GoldinMeadow, 2010; Van Gog, Paas, Marcus, Ayres \& Sweller, 2009; Youssef, Ayres \& Sweller, 2012). Indeed, human cognitive architecture and the knowledge acquisition process are supposed to have evolved in a similar way to biological structures (Sweller \& Sweller, 2006). The limited working memory constrains the learning of new information for which the human being is not adapted. Thus, reducing cognitive load through instructions should promote learning. That is the main claim of the cognitive load theory (Sweller et al., 2011). Until recently, the limited capacity of working memory was thought to apply to the acquisition of all kinds of information (Paas \& Sweller, 2012). But, as our system evolved to easily process primary knowledge, the cost in working memory is minimized. The processing of primary knowledge, even extremely complex, does not imply working memory cost (e.g. speaking is a complex activity combining motor skills, sounds, gesture, etc.). However, when an individual is faced with secondary knowledge, she or he doesn't have the abilities inspired 
by genetics to automatically assimilate information. The cognitive load theory then applies only to secondary knowledge (Sweller, 2008).

\section{$2 \quad$ Present study}

As far as we know, no study investigated the influence of primary and secondary knowledge content on individuals' performance and motivation in a reasoning task. In this paper, our aim is to test whether the effortful and motivating nature of primary knowledge could facilitate performance and engagement in a reasoning task (involving normative rules as secondary knowledge), challenging the evolutionary model of knowledge. To this end, we conducted two experiments. Each participant was faced with conditional problems involving primary knowledge content (food) or secondary knowledge content (grammatical rules). Problems involved unknown words so that familiarity and prior knowledge did not influence responses. As a matter of fact, our participants spend more time learning and applying secondary knowledge such as grammatical rules than dealing with how to process food so that it can be eaten (Beck \& Richard, 2010; Guichemerre, 2011) and, in any case, none of them found the themes used familiar from near or far. Problems had thus the same level of abstraction with a shade of primary or secondary knowledge. As in studies in logical reasoning, we assessed participants' performance. We also wanted to include important factors in learning such as emotional and cognitive engagement, confidence in given responses and the perceived cognitive load. The main goal was to highlight that primary knowledge positively influence those variables comparing to secondary knowledge (Hypothesis 1 ).

In order to challenge the evolutionary model of knowledge, we also manipulated the added or extrinsic cognitive load of the tasks. Indeed, secondary knowledge is supposed to consume cognitive resources whereas primary knowledge is not. Thus, adding an additional cognitive load with a second task should impede secondary content to a greater extent than primary knowledge content specifically regarding performance (Hypothesis 2). To this aim, we used words in reversed order in the problems (Experiment 1) and a Dot Memory Task (Experiment 2). In this paper, the cognitive load thus takes two forms: (i) an independent variable (the manipulated cognitive load with reversed words or with a Dot Memory Task) in order to explore whether its high cognitive load modality influences secondary knowledge content mainly and (ii) a dependent variable (the perceived cognitive load experienced by the participants that must not exceed working memory capacity) in order to control whether primary knowledge content involves less cognitive load which should be an interesting fact for learning considerations. 
Finally, we examined the influence of the primary/secondary knowledge presentation order. Primary knowledge presented first should motivate participants for the continuation of the task (for secondary knowledge problems) (Hypothesis 3).

\section{Experiment 1}

\subsection{Method}

\subsubsection{Participants}

Participants were 126 university students in France (21 men, 105 women, mean age was 22 \pm 7 ), approached by University Facebook groups from five cities. Participants estimated their level in math at 48/100 ( \pm 27$)$ and they liked logic games at 67/100 ( \pm 26$)$.

\subsubsection{Materials}

Six conditional rules were created. Three of them referred to primary knowledge (rules about how to eat unknown items) and three of them referred to secondary knowledge (unknown grammatical rules). Each participant read the following instructions:

Six statements will be presented. These statements must be considered as true. For each statement, several proposals will be proposed. You will have to judge their validity.

On one internet page, a conditional statement was displayed. For example, participants read:

In a community in Jamaica, if an ugli is picked up red, then it is peeled entirely to be eaten (primary knowledge content involving rules about food, noted K1 in detail results).

In Quenya, if a strong verb is conjugated to the perfect, then this strong verb ends with-ie (secondary knowledge content involving grammatical rules, noted $\mathrm{K} 2$ in detail results).

Participants then had to answer four questions involving $M P, M T$, AC and DA (e.g. MP, "In a community in Jamaica, an ugli is picked up red. Is this ugli peeled entirely to be eaten?"). They could answer "yes" (MP), "no" (MT) or "maybe" (AC and DA as correct answers) by putting a cross in the corresponding box. The first conditional statement contained about 20 words in French, the second 25 and the third 30, whether it involved primary or secondary knowledge content. Every conditional statement involved unfamiliar words or rules (such as "ugli" or a non-existent grammatical rule) so that familiarity and prior knowledge influence the task as little as possible. The 
interest in the two knowledge types themes were assessed in a previous survey involving 571 respondents: primary knowledge theme $(\mathrm{M}=32.56 \pm 33.25)$ did not elicit higher interest compared with secondary knowledge theme $(M=31.64 \pm 32.74)(p=.73)$. No participant told that they were familiar with the terms used.

The added cognitive load was manipulated between groups by reversing the words in several parts of the task. By asking participants to read in an unusual way, the extrinsic cognitive load of the task was more important than if words were presented in the conventional order. Participants in the high cognitive load modality (noted "CL high" in detail results) were confronted with a conditional statement and questions with reversed words. The following example resumes the primary knowledge example cited above:

Conditional statement: Eaten be to entirely peeled is it then, red up picked is ugli an if, Jamaica in community a in.

Question: In a community in Jamaica, an ugli is picked up red. Eaten be to entirely peeled ugli this is?

Participants were told to read the reversed words sentences from the right to the left. Participants in the low cognitive load modality (noted "CL low" in detail results) read words in the conventional order.

\subsubsection{Procedure}

The experiment was conducted online with Qualtrics and 20 minutes long. Each participant was presented with three conditional statements involving primary knowledge and three conditionals statements involving secondary knowledge: one conditional statement on each page. The presentation order was counterbalanced. In addition to their (i) performance (in percentage), for each conditional statement, participants had to provide information on an analogic visual scale (from 0 to 100): How much they (ii) "enjoy thinking about the questions" (emotional investment); How much they (iii) "wanted to find the correct answers" (cognitive investment/motivation); How much they were (iv) "confident about their given answers" (confidence); and How much they agreed with two sentences (v) "the subject was complex" and "you concentrated a lot to do the task" (perceived cognitive load). The (vi) speed (number of problems solved in one minute) to complete each page was also measured. 
Finally, participants responded to some personal information including their estimated level in math and their enthusiasm for solving logical problems.

\subsubsection{Data analyses}

We expect an influence of the types of knowledge on every dependent variable. That is, primary knowledge should increase performance, emotional and cognitive investment, confidence and should decrease the perceived cognitive load (Hypothesis 1). We also expect an interaction between the types of knowledge and the cognitive load manipulated: the high cognitive load modality should only hinder performance on secondary knowledge content problems (Hypothesis 2). Linear mixed-effects models and Pearson correlations were used to analyze data. The Wald $\chi^{2}$, estimate and its Standard Error (SE) were reported for main analyses. Means were noted M and standard deviation ( \pm ). All variables were scaled for analyses and performed with R 3.3.2. Non-significant results were not presented.

\subsection{Results and discussion}

\subsubsection{Preliminary analyses}

The 20 words long conditional statements $(M=65.38 \pm 25.91)$ did not elicit different performances than the 25 words long $(M=62.30 \pm 24.60)$ and the 30 words long ones $(M=65.57 \pm 26.18)(p s>.08)$, but the 25 words long ones elicited lower performance than the 30 words long ones $(p=.03)$. Regarding the influence of the inference type, as expected, $M P$ problems $(M=83.47 \pm 28.62)$ elicited higher performance but did not differ significantly from $M T$ problems $(\mathrm{M}=78.44 \pm 29.72)(p=.39)$. These two types of inference led to higher performances than AC problems $(M=49.07 \pm 39.18)$ and DA problems $(\mathrm{M}=46.69 \pm 39.50)(p s<.001)$.

\subsubsection{The two knowledge types (Hypothesis 1)}

Compared with secondary knowledge, primary knowledge elicited higher performance and speed, enjoyment of the task, wish to find the correct answers and confidence in given responses as well as a lower perceived cognitive load (Table 1 and Figure 1). More accurately, the 30 words long conditional sentences highlighted a significant difference in performance $\left(\mathrm{M}_{\mathrm{K} 1}=77.18 \pm 23.03 \mathrm{vs}\right.$. $\left.\mathrm{M}_{\mathrm{K} 2}=53.97 \pm 23.96\right)$ (estimate $\left.=-0.89, \mathrm{SE}=0.09 ; \chi^{2}=101.89, p<.001\right)$ as well as $M P$ problems $\left(\mathrm{M}_{\mathrm{K} 1}=86.51 \pm 26.73\right.$ vs. $\left.\mathrm{M}_{\mathrm{K} 2}=80.42 \pm 30.19\right)$ (estimate=-0.21, $\left.\mathrm{SE}=0.09 ; \chi^{2}=5.96, p=.02\right), M T$ problems 
$\left(\mathrm{M}_{\mathrm{K} 1}=81.75 \pm 26.20\right.$ vs. $\left.\mathrm{M}_{\mathrm{K} 2}=75.13 \pm 32.64\right)$ (estimate=-0.22, $\left.\mathrm{SE}=0.09 ; \chi^{2}=5.78, p=.02\right)$ and $\mathrm{AC}$ problems $\left(\mathrm{M}_{\mathrm{K} 1}=53.97 \pm 36.72\right.$ vs. $\left.\mathrm{M}_{\mathrm{K} 2}=44.18 \pm 41.06\right)\left(\right.$ estimate=-0.25, $\left.\mathrm{SE}=0.07 ; \chi^{2}=11.21, p=.001\right)$.

\subsubsection{The reversed words (Hypothesis 2)}

Overall, compared with the low cognitive load modality, the high cognitive load modality elicited lower performance $\left(\mathrm{M}_{\mathrm{CL} \text { low }}=67.34 \pm 19.86\right.$ vs. $\left.\mathrm{M}_{\mathrm{CL} \text { high }}=60.99 \pm 21.35\right)$ (estimate=-0.33, $\mathrm{SE}=0.16$; $\left.\chi^{2}=4.22, p=.04\right)$, higher wish to find the correct answers $\left(\mathrm{M}_{\mathrm{CL} \text { low }}=55.67 \pm 30.12 \mathrm{vs} . \mathrm{M}_{\mathrm{CL}}\right.$ high $=64.68 \pm 27.08)$ (estimate=0.30, $\left.\mathrm{SE}=0.15 ; \chi^{2}=3.96, p=.04\right)$ and lower speed $\left(\mathrm{M}_{\mathrm{CL} \text { low }}=4.47 \pm 7.14 \mathrm{vs}\right.$. $\left.\mathrm{M}_{\mathrm{CL} \text { high }}=3.13 \pm 4.44\right)\left(\right.$ estimate $\left.=-0.21, \mathrm{SE}=0.08 ; \chi^{2}=6.54, p=.01\right)$.

The interaction between the additional manipulated cognitive load and the type of knowledge is significant regarding the performance (estimate $=-0.31, \mathrm{SE}=0.03 ; \chi^{2}=123.01, p<.001$ ) (Figure 2). The results of the influence of reversing the words were then analyzed regarding primary knowledge and secondary knowledge separately. Regarding secondary knowledge content problems, the high cognitive load modality led to lower performance ( $M_{C L ~ l o w}=65.44 \pm 20.83$ vs. $M_{C L \text { high }}=55.89 \pm 20.13$ ) (estimate=0.48, $\left.\mathrm{SE}=0.16 ; \chi^{2}=7.05, p=.009\right)$ and tended to decrease speed $\left(\mathrm{M}_{\mathrm{CL} \text { low }}=7.85 \pm 2.50 \mathrm{vs} . \mathrm{M}_{\mathrm{CL}}\right.$ high $=6.71 \pm 2.42)\left(\right.$ estimate $\left.=0.20, \mathrm{SE}=0.10 ; \chi^{2}=3.51, p=.06\right)$. Regarding primary knowledge content problems, the high cognitive load modality led to higher wish to find the correct answers $\left(\mathrm{M}_{\mathrm{CL}}\right.$ $l_{\text {low }}=59.46 \pm 28.67$ vs. $\left.\mathrm{M}_{\mathrm{CL} \text { high }}=69.11 \pm 25.35\right)$ (estimate=0.33, $\left.\mathrm{SE}=0.16 ; \chi^{2}=4.12, p=.04\right)$ and lower speed $\left(\mathrm{M}_{\mathrm{CL} \text { low }}=4.93 \pm 8.29\right.$ vs. $\left.\mathrm{M}_{\mathrm{CL} \text { high }}=3.38 \pm 4.33\right)\left(\right.$ estimate=-0.22, $\left.\mathrm{SE}=0.11 ; \chi^{2}=3.93, p=.05\right)$.

\subsubsection{The presentation order (Hypothesis 3)}

The presentation order did not influence overall data. Concerning this variable, as it directly involved knowledge type used, data were analyzed regarding primary and secondary knowledge separately. The presentation order had an influence on secondary knowledge content problems only. When primary knowledge content problems were presented first, participants had less wish to find the correct answers to secondary knowledge content problems $\left(\mathrm{M}_{\mathrm{K} 1 \text { first }}=51.73 \pm 28.25 \mathrm{vs}\right.$. $\mathrm{M}_{\mathrm{K} 2}$ first $=59.98 \pm 31.18)\left(\right.$ estimate $\left.=0.33, \mathrm{SE}=0.16 ; \chi^{2}=4.36, p=.04\right)$ but felt less cognitive load $\left(\mathrm{M}_{\mathrm{K} 1}\right.$ first $=44.29 \pm 23.07$ vs. $\left.\mathrm{M}_{\mathrm{K} 2 \text { first }}=52.18 \pm 23.92\right)\left(\right.$ estimate=0.31, $\left.\mathrm{SE}=0.15 ; \chi^{2}=4.64, p=.03\right)$.

\subsubsection{Additional analyses: the level in math}

The higher the estimated level in math was, the higher the performance $(r=0.10 ; p<.001)$, the wish to find the correct answers $(r=0.17 ; p<.001)$, the confidence in given responses $(r=0.19 ; p<.001)$ 
were and the less the perceived cognitive load was $(r=-0.21 ; p<.001)(-0.006<$ estimates $<0.009$, $0.002<$ SEs $\left.<0.003 ; 4.85<\chi^{2} s<9.05, .003<p s<.02\right)$.

\subsubsection{Discussion}

Experiment 1 corroborated our first assumption: compared with secondary knowledge, primary knowledge increased performance, speed/efficiency, emotional and cognitive investment and decreased perceived cognitive load. It then highlighted that high cognitive load reduced performance regarding secondary knowledge content problems only (Hypothesis 2). Secondary knowledge would therefore need more cognitive resources available to be treated. Moreover, we surprisingly found an influence of the presentation order (Hypothesis 3). Primary knowledge seemed to preserve participants' motivation whether they were presented first. Also, presenting primary knowledge content problems first reduced the cognitive load experienced in secondary knowledge content problems. The fact that participants expressed less wish to find the correct answer when primary knowledge was presented first could be explained by the perceived difference in motivation between the two knowledge types; that is participants might feel discouraged by the perceived difficulty of secondary knowledge compared to primary knowledge that they saw first. The aim of Experiment 2 is to consolidate these results regarding hypotheses 1 and 2 and investigate hypothesis 3 with another task to manipulate cognitive load and another population.

\section{Experiment 2}

Reversing the order of words in problems seemed to increase indirectly the cognitive load as experiment 1 showed the speed of problem-solving and the performance facing a high cognitive load modality were decreased. Nevertheless, participants did not reflect that this additional task had an impact on their perceived cognitive load. The goal of the experiment 2 is thus to consolidate these results by challenging them with another task well-known to diminish working memory resources:

the Dot Memory Task (Bethell-Fox \& Shepard, 1988; De Neys, 2006; Miyake, Friedman, Rettinger, Shah \& Hegarty, 2001). Moreover, several studies showed that adolescents (especially older adolescents) did not reason in a highly different way compared with adults (Khemlani \& JohnsonLaird, 2012; Markovits \& Lortie-Forgues, 2011). Thus, we wanted to challenge the evolutionary approach of knowledge with younger participants as much, if not more, subject to demotivation regarding secondary knowledge.

\subsection{Method}




\subsubsection{Participants}

Participants were 101 students from high school (56 men, 45 women, mean age was 15 \pm 1 ). Their estimated their level in math at 50/100 ( \pm 28$)$, they like logic games at $66 / 100( \pm 31)$ and $81 \%$ $(n=82)$ never played (or very little) logic games. None found the themes familiar

\subsubsection{Materials}

The same conditional rules as in Experiment 1 were used but we added words to make each conditional statements about 30 words (e.g. "In a community in Jamaica, if an ugli is picked up red, then it is peeled entirely to be eaten" became "In a community in Jamaica, a country whose capital is Kingston, if a ugli is picked up red, then it is peeled entirely to be eaten on the sand of Frenchman's cove"). Then, instead of a reversed word task to manipulate the cognitive load, a Dot Memory Task was used in order to replicate Experiment 1's results and challenge our assumptions ( $c f$. Procedure).

\subsubsection{Procedure}

The procedure was similar to that of Experiment 1, except for three changes. First, the experiment was a paper-pencil one during school time. Second, a Dot Memory Task protocol has been applied. Before each sheet of conditional statement, problems and analogic visual scale, participants had to memorize the position of several points in a table $(3 * 3)$ projected on the blackboard during 850 milliseconds. After answering each question on the sheet, they had to fill in a table with the points remembered on the next sheet. The aim was to load working memory while answering questions. Participants in the high cognitive load modality had to remember a four points pattern (of which two maximum were side-by-side) and participants in the low cognitive load modality had to remember a 3 aligned points pattern (Figure 3). Each participant had four minutes to complete questions and have to wait to go to the next page and fill in the table. Thus the speed was not measured. Third, before asking participants' personal information, at the end of the experiment, a last sheet was added, similar to other conditional sheets: the conditional statement was "If A exists, then B exists" and problems looked like "A exists. Does B exist?". These last logical problems should allow an overview of the influence of presentation order on every dependent variable more precisely than in Experiment 1. 


\subsubsection{Data analyses}

Statistical analyzes were similar to those of Experiment 1. In a minor way, between and within ttests (Dot Memory Task performance) as well as between subjects' ANOVA (last AB problems) were used. Non-significant results were not presented.

\subsection{Results and discussion}

\subsubsection{Preliminary analyses}

The conditional statements presented first $(\mathrm{M}=52.60 \pm 20.78)$ did not elicit different performances than the conditional statements presented second $(49.75 \pm 20.86)$ and those presented third/last $(\mathrm{M}=53.71 \pm 22.96) \quad(p s<.08)$, but the conditional statements presented second elicited lower performance than those presented third (estimate $=0.5, \mathrm{SE}=0.11 ; \chi^{2}=5.13, p=.02$ ) (similar pattern to Experiment 1). Regarding the influence of inference type, as expected, $M P$ problems ( $M=82.67 \pm 29.96)$ elicited higher performance. They differed significantly from MT problems $(M=72.11 \pm 32.03)$ (estimate $=-0.38, \mathrm{SE}=0.10 ; \chi^{2}=22.02, p<.001$ ). These two types of inference led to higher performance than AC $(\mathrm{M}=28.05 \pm 33.16)$ and $\mathrm{DA}$ problems $(\mathrm{M}=25.25 \pm 31.64)(p s<.001)$.

\subsubsection{The two knowledge types (Hypothesis 1)}

Compared with secondary knowledge, primary knowledge elicited higher performance, enjoyment of the task, wish to find the correct answers and confidence in given responses as well as a lower perceived cognitive load (Table 2 and Figure 4). More accurately, conditional statements presented second $\left(\mathrm{M}_{\mathrm{K} 1}=52.97 \pm 20.09\right.$ vs. $\left.\mathrm{M}_{\mathrm{K} 2}=46.53 \pm 21.22\right)$ (estimate $=-0.31, \mathrm{SE}=0.12 ; \chi^{2}=6.18$, $p=.01)$ and third $\left(\mathrm{M}_{\mathrm{K} 1}=64.11 \pm 22.75\right.$ vs. $\left.\mathrm{M}_{\mathrm{K} 2}=43.32 \pm 17.99\right)$ (estimate $=-0.90, \mathrm{SE}=0.11 ; \chi^{2}=59.73$, $p<.001)$ highlighted a significant difference in performance as well as MP problems $\left(\mathrm{M}_{\mathrm{K} 1}=87.46 \pm 27.43\right.$ vs. $\left.\mathrm{M}_{\mathrm{K} 2}=77.89 \pm 31.72\right)$ (estimate=-0.32, $\left.\mathrm{SE}=0.10 ; \chi^{2}=10.69, p=.001\right)$, MT problems $\left(\mathrm{M}_{\mathrm{K} 1}=75.58 \pm 29.77\right.$ vs. $\left.\mathrm{M}_{\mathrm{K} 2}=68.65 \pm 33.93\right)$ (estimate $\left.=-0.22, \mathrm{SE}=0.10 ; \chi^{2}=4.30, p=.04\right)$ and $\mathrm{AC}\left(\mathrm{M}_{\mathrm{K} 1}=34.98 \pm 33.46\right.$ vs. $\left.\mathrm{M}_{\mathrm{K} 2}=21.12 \pm 31.52\right)$ (estimate $\left.=-0.42, \mathrm{SE}=0.10 ; \chi^{2}=17.90, p<.001\right)$.

\subsubsection{The Dot Memory Task (Hypothesis 2)}

The mean Dot Memory Task performance $97.92( \pm 6.55)$ regarding the low cognitive load modality and $67.92( \pm 27.12)$ regarding the high cognitive load modality $(t(99)=7.80, p<.001)$. The knowledge type did not influence the Dot Memory Task performance $(p=.26)$. 
Compared with the low cognitive load modality, the high cognitive load modality elicited higher performance overall $\left(\mathrm{M}_{\mathrm{CL} \text { low }}=50.08 \pm 15.80\right.$ vs. $\left.\mathrm{M}_{\mathrm{CL} \text { high }}=53.77 \pm 17.52\right)$ (estimate=0.30, $\mathrm{SE}=0.15$; $\left.\chi^{2}=4.37, p=.04\right)$. It was particularly observed for primary knowledge content $\left(\mathrm{M}_{\mathrm{CL} \text { low }}=52.95 \pm 15.65\right.$ vs. $\mathrm{M}_{\mathrm{CL} \text { high }}=59.75 \pm 18.23$ ) (estimate=0.30, $\left.\mathrm{SE}=0.15 ; \chi^{2}=4.36, p=.04\right)$ illustrated by a significant interaction between the additional cognitive load modality and the knowledge type (estimate $=0.37$, $\mathrm{SE}=0.04 ; \chi^{2}=20.66, p<.001$ regarding the performance) (Figure 5). This result could highlight a greater interest of high school students for the complex Dot Memory Task modality that was expressed orally during the experiment.

\subsubsection{The presentation order (Hypothesis 3)}

Participants had higher overall performance when primary knowledge content problems were presented first $\left(\mathrm{M}_{\mathrm{K} 1 \text { first }}=55.29 \pm 17.15\right.$ vs. $\left.\mathrm{M}_{\mathrm{K} 2 \text { first }}=48.55 \pm 15.76\right)\left(\right.$ estimate= $=0.36, \mathrm{SE}=0.15 ; \chi^{2}=5.82$ $p=.02)$ and perceived less cognitive load $\left(\mathrm{M}_{\mathrm{K} 1 \text { first }}=40.72 \pm 25.27\right.$ vs. $\left.\mathrm{M}_{\mathrm{K} 2 \text { first }}=50.53 \pm 27.81\right)$ (estimate $=0.35, \mathrm{SE}=0.16 ; \chi^{2}=4.57, p=.03$ ).

As the presentation order directly involved knowledge type used, data were analyzed regarding primary and secondary knowledge separately. Presentation order had an influence on secondary knowledge content questions only. When primary knowledge content problems were presented first, participants had higher performance regarding secondary knowledge content problems $\left(\mathrm{M}_{\mathrm{K} 1}\right.$ first $=52.88 \pm 15.68$ vs. $\mathrm{M}_{\mathrm{K} 2 \text { first }}=41.84 \pm 11.73$ ) (estimate=0.61, $\mathrm{SE}=0.15 ; \chi^{2}=17.15, p<.001$ ), were more

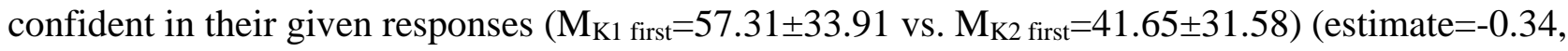
$\left.\mathrm{SE}=0.16 ; \chi^{2}=4.35, p=.04\right)$ and perceived lower cognitive load $\left(\mathrm{M}_{\mathrm{K} 1 \text { first }}=40.62 \pm 24.98 \mathrm{vs} . \mathrm{M}_{\mathrm{K} 2}\right.$ first $=56.80 \pm 25.57)$ (estimate $\left.=0.61, \mathrm{SE}=0.17 ; \chi^{2}=12.89, p<.001\right)$ (Figure 6).

\subsubsection{Additional analyses: the level in math}

The higher the estimated level in math was, the higher the performance $(r=0.24 ; p<.001)$ and the confidence in given responses $(r=0.34 ; p<.001)$ were and the less the perceived cognitive load was $(r=-0.19 ; p<.001)\left(-0.006<\right.$ estimates $\left.<0.009, \mathrm{SEs}=0.003 ; 4.61<\chi^{2} s<19.03, .001<p s<.03\right)$.

\subsubsection{The last logical problems AB}

Regarding the last $\mathrm{AB}$ conditional problems, presentation order influenced significantly the confidence in $\mathrm{AB}$ given responses $\left(\mathrm{M}_{\mathrm{K} 1 \text { first }}=69.01 \pm 25.17\right.$ vs. $\left.\mathrm{M}_{\mathrm{K} 2 \text { first }}=50.55 \pm 32.83\right)(F(1,96)=9.81$; $\left.p=.002 ; \eta^{2}=0.09\right)$ and marginally the perceived cognitive load $\left(\mathrm{M}_{\mathrm{K} 1 \text { first }}=41.99 \pm 25.32 \mathrm{vs} . \mathrm{M}_{\mathrm{K} 2}\right.$ 
first $=50.27 \pm 26.92)\left(F(1,96)=3.06 ; p=.08 ; \eta^{2} p=0.03\right)$. The manipulated cognitive load influenced significantly the perceived cognitive load on AB problems $\left(F(1,96)=15.90 ; p<.001 ; \eta^{2}{ }_{p}=0.14\right)\left(\mathrm{M}_{\mathrm{CL}}\right.$ low $=36.05 \pm 23.70$ vs. $M_{C L \text { high }}=55.02 \pm 25.53$ ), validating the Dot Memory Task procedure.

\subsubsection{Discussion}

Experiment 2 replicated the main findings of Experiment 1: compared with secondary knowledge, primary knowledge elicited higher performance, emotional and cognitive investments, confidence as well as lower perceived cognitive load (Hypothesis 1). Experiment 2 also highlighted new data about the impact of presentation order (Hypothesis 3). The results clearly showed that performance and confidence were more important and perceived cognitive load was lower when primary knowledge content problems were presented first. Moreover, primary knowledge content problems were not influenced by presentation order, leading us to think that they were intrinsically motivating, whereas secondary knowledge content problems increased their cognitive load.

\section{General discussion}

This empirical paper proposes to bring together the evolutionary educational psychology and study on logical reasoning. Indeed, normative logic can be considered as secondary knowledge: it requires motivation, time and effort to be learned. The everyday life logic is primary knowledge: heuristics are acquired without effort and very quickly. In order to promote the individuals' involvement in a logical reasoning task, it would seem interesting to rely on primary knowledge. We conducted two experiments varying (i) the content of conditional problems (primary or secondary knowledge), (ii) the cognitive load and (iii) the content presentation order. Even if the words were unknown to the participants, the results highlighted a very important positive effect of primary knowledge on logical reasoning in terms of performance, emotional and cognitive engagement, confidence and perceived cognitive load making primary knowledge seem to be intrinsically motivating. Presenting primary knowledge first would thus be a positive point to foster engagement in reasoning tasks.

First, for a similar level of abstraction, the two experiments presented in this paper undoubtedly showed that a primary knowledge content promoted performance (for the majority of inferences), emotional and cognitive engagement and confidence and decreased the perceived cognitive load (Hypothesis 1). These results fitted with Geary's theory (Geary \& Berch, 2016) for which primary knowledge is intrinsically motivating and easily processed (requires less cognitive resources). This 
ease of processing would give a false impression of familiarity. The present research showed that primary knowledge does not need to be familiar (as all participants noted they were not familiar with the themes used) to be motivating and processed better: we seem to be predisposed for them as we are for deontic rules (Cosmides \& Tooby, 2004; Gigerenzer \& Hug, 1992). Other studies will be able to address this issue by comparing the influence of the familiar or unfamiliar nature of the contents. In addition, differences in performance between primary and secondary knowledge content problems were significant for the later problems presented: secondary knowledge might induce fatigue or may disengage individuals more easily than primary knowledge.

Second, in Experiment 1, a high manipulated cognitive load elicited lower performance and this effect was only showed regarding secondary knowledge content problems (Hypothesis 2). It fits with the cognitive load theory (Sweller, 2008): the cognitive load applied only to secondary knowledge. The results from Experiment 2 fit better with the desirable difficulty approach (Bjork \& Bjork, 2011): a high cognitive load (Dot Memory Task) would favor the individuals' interest and engagement in the task leading to higher performances. This second effect was showed especially for primary knowledge content that would require fewer cognitive resources than secondary knowledge content and would allow allocation of resources for the Dot Memory Task whereas secondary knowledge would saturate working memory capacity more easily.

Third, presenting primary knowledge first had an interesting overall effect in Experiment 2: participants showed higher performances and lower perceived cognitive load (Hypothesis 3). For both experiments, the presentation order did not influence primary knowledge content problems in an important way. However, presenting primary knowledge first influenced positively performances as well as confidence and decreased the perceived cognitive load regarding secondary knowledge content problems. The higher performance can be explained by a learning bias (one has better performance regarding the problems presented later). Nevertheless, the absence of a presentation order effect on primary knowledge underlined a motivating feature of primary knowledge and a demotivating feature of secondary knowledge. The presentation order did not influence the performance on the $\mathrm{AB}$ problems leading us to think that learning was not involved in our tasks (actually, it was not designed for it). In the context of a longer task, there is no doubt that interesting differences would be observed regarding the influence of the primary/secondary knowledge presentation order. 
Moreover, for both experiments, the self-estimated level in math had a positive influence on performance, confidence and even on the wish to find the correct answers and decreased the perceived cognitive load. It would be an argument for mathematical abilities to be linked to logical skills (Morsanyi, Devine, Nobes \& Szücs, 2013).

These experiments with conditionals (Bonnefon et al., 2008) do not allow to highlight relations between systems 1/2 and primary/secondary knowledge, nor to investigate the cognitive implications of knowledge types. Similar studies involving syllogisms with belief bias could help explore this aspect. However, the two experiments presented in this paper demonstrated that secondary knowledge used more cognitive resources than primary knowledge. In addition, new studies could challenge the influence of primary and secondary knowledge by using other themes than food and grammatical rules in order to confirm the positive impact of primary knowledge. The results presented are encouraging and support the recent studies highlighting a positive effect of using primary knowledge in secondary knowledge learning (Paas \& Ayres, 2014). The influence of the two knowledge types should be tested in actual learning tasks.

This paper proposes to lay the foundations for a new approach to formal logic learning. Compared with a secondary knowledge content, using a primary knowledge content in conditional problems influenced positively performance, emotional and cognitive engagement and confidence and decreased the perceived cognitive load. Primary knowledge seemed to have an intrinsically motivating effect and was not influenced by the presentation order, whereas secondary knowledge seemed to benefit from the fact that primary knowledge was presented first. Educational institutes are not used to presenting primary knowledge, they directly put learners faced with secondary knowledge, leading to difficulties to maintain learners' motivation. Primary knowledge content would thus be a good introduction to a new topic: it would motivate participants for future secondary knowledge tasks. Nevertheless, the evolutionary educational psychology brings interesting perspectives in the context of logic learning and general learning.

\section{$6 \quad$ Ethical approval}

This study was conducted in accordance with the ethical standards of the institutional and national guidelines and with the Declaration of Helsinki (2008). Informed consent was obtained from all individual participants included in the study.

\section{Conflict of Interest}


The authors declare that the research was conducted in the absence of any commercial or financial relationships that could be construed as a potential conflict of interest.

\section{$8 \quad$ References}

Barker-Plummer, D., Barwise, J., \& Etchemendy, J. (2008). Tarski's world. Stanford, Calif: CSLI Publications.

Barrows, H. S. (1994). Practice-based Learning: Problem-based Learning Applied to Medical Education. Southern Illinois University, School of Medicine.

Beck, F., \& Richard, J.-B. (2010). Les comportements de santé des jeunes. Inpes. http://inpes.santepubliquefrance.fr/Barometres/barometre-sante-2010/comportement-santejeunes/pdf/Alimentation-12-30-ans.pdf

Bethell-Fox, C. E., \& Shepard, R. N. (1988). Mental rotation: Effects of stimulus complexity and familiarity. Journal of Experimental Psychology: Human Perception and Performance, 14(1), 12. doi: 10.1037/0096-1523.14.1.12

Bjork, E. L., \& Bjork, R. A. (2011). Making things hard on yourself, but in a good way: Creating desirable difficulties to enhance learning. In FABBS Foundation, Gernsbache, M. A., \& Pomerantz, J. R. (Eds.) Psychology and the real world: Essays illustrating fundamental contributions to society, 56-64.

Bonnefon, J. F., Eid, M., Vautier, S., \& Jmel, S. (2008). A mixed Rasch model of dual-process conditional reasoning. The Quarterly Journal of Experimental Psychology, 61(5), 809-824.

Braver, T. S., Krug, M. K., Chiew, K. S., Kool, W., Westbrook, J. A., Clement, N. J., Adcock, R. A., Barch, D. M., Botvinick, M. M., Carver, C. S., Cools, R., Custers, R., Dickinson, A., DWeck C. S., Fishbach, A., Gollwitzer, P. M., Hess, T. M., Isaacowitz, M. M., Murayama, K., Pessoa, L., Samanez-Larkin, G. R., \& Somerville, L. H. (2014). Mechanisms of motivation-cognition interaction: challenges and opportunities. Cognitive, Affective, \& Behavioral Neuroscience, 14(2), 443-472. doi: 10.3758/s 13415-014-0300-0

Carroll, L. (1896). Symbolic Logic, Part I: Elementary. London: Macmillan.

Chi, M. T., \& Wylie, R. (2014). The ICAP framework: Linking cognitive engagement to active learning outcomes. Educational Psychologist, 49(4), 219-243. doi:

$10.1080 / 00461520.2014 .965823$ 
Cosmides, L., \& Tooby, J. (2004). Knowing thyself: The evolutionary psychology of moral reasoning and moral sentiments. The Ruffin Series of the Society for Business Ethics, 4, 93-128. doi: 10.5840/ruffinx200447

Cosnefroy, O., Nurra, C., \& Dessus, P. (2016). Analyse dynamique de la motivation des élèves en début de scolarité obligatoire en fonction de la nature de leurs interactions avec l'enseignant. Éducation et formations, (90), 29-51. doi: hal-01306393

De Neys, W. (2006). Dual processing in reasoning: Two systems but one reasoner. Psychological science, 17(5), 428-433. doi: 10.1111/j.1467-9280.2006.01723.x

De Neys, W., \& Bonnefon, J. F. (2013). The 'whys' and 'whens' of individual differences in thinking biases. Trends in Cognitive Sciences, 17(4), 172-178. doi: 10.1016/j.tics.2013.02.001

De Neys, W., \& Everaerts, D. (2008). Developmental trends in everyday conditional reasoning: The retrieval and inhibition interplay. Journal of Experimental Child Psychology, 100(4), 252-263. doi: 10.1016/j.jecp.2008.03.003

De Neys, W., \& Feremans, V. (2013). Development of heuristic bias detection in elementary school. Developmental Psychology, 49(2), 258. doi: 10.1037/a0028320

De Neys, W., Schaeken, W., \& d'Ydewalle, G. (2005). Working memory and everyday conditional reasoning: Retrieval and inhibition of stored counterexamples. Thinking \& Reasoning, 11(4), 349381. doi: 10.1080/13546780442000222

Dominowski, R. L. (1995). Content effects in Wason's selection task. In Newstead, S. E., \& Evans, J. S. B. T. (Eds), Perspectives on thinking and reasoning: Essays in honour of Peter Wason, (pp.41$65)$.

Ellis, G. F. (2008). Commentary on "An evolutionarily informed education science” by David C. Geary. Educational Psychologist, 43(4), 206-213. doi: 10.1080/00461520802392216

Evans, J. S. B. T. (2005). Deductive reasoning. In Holyoak, K. J., \& Morrison R. G., The Cambridge Handbook of Thinking and Reasoning, (pp.169-184). New York: Cambridge University Press.

Evans, J. S. B., \& Frankish, K. E. (2009). In two minds: Dual processes and beyond. Oxford University Press.

Evans, J. S. B., Handley, S. J., \& Bacon, A. M. (2009). Reasoning under time pressure: A study of causal conditional inference. Experimental Psychology, 56(2), 77-83. doi: 10.1027/16183169.56.2.77

Evans, J. S. B., Handley, S. J., Neilens, H., \& Over, D. E. (2007). Thinking about conditionals: A study of individual differences. Memory \& Cognition, 35(7), 1772-1784. doi: 10.3758/BF03193509 
Geary, D. C. (2007). Educating the evolved mind: Conceptual foundations for an evolutionary educational psychology. In J. S. Carlson \& J. R. Levin (Eds.), Educating the evolved mind: Conceptual foundations for an evolutionary educational psychology (pp. 1-99). Greenwich, CT: Information Age.

Geary, D. C. (2008). An evolutionarily informed education science. Educational Psychologist, 43(4), 179-195. doi: 10.1080/00461520802392133

Geary, D. C. (2012). Application of evolutionary psychology to academic learning. In Roberts, S. C. (Ed.), Applied evolutionary psychology, (pp.78-92).

Geary, D. C., \& Bjorklund, D. F. (2000). Evolutionary developmental psychology. Child development, 71(1), 57-65. doi: 10.1111/1467-8624.00118

Geary, D. C., \& Berch, D. (2016). Evolution and Children's Cognitive and Academic Development. In Geary, D. C., \& Berch, D. (Eds.), Evolution and Children's Cognitive and Academic Development (pp.217-249). Switzerland: Springer International Publishing. doi: 10.1007/978-3319-29986-0_9

Geary, D. C., \& Berch, D. (2015). Evolutionary approaches to understanding children's academic achievement. In R. A. Scott \& S. M. Kosslyn (Eds.), Emerging Trends in the Social and Behavioral Sciences. Hoboken, NJ: Wiley. doi: 10.1002/9781118900772.etrds0123

Gigerenzer, G., \& Hug, K. (1992). Domain-specific reasoning: Social contracts, cheating, and perspective change. Cognition, 43(2), 127-171. doi: 10.1016/0010-0277(92)90060-U

Glenberg, A. M., Goldberg, A. B., \& Zhu, X. (2011). Improving early reading comprehension using embodied CAI. Instructional Science, 39(1), 27-39. doi: 10.1007/s11251-009-9096-7

Guichemerre, C. (2011). Enquête vie de campus. Université de Bordeaux. http://www.cueaquitaine.fr/docs/poleetudes/conditions_vie/tdb1.pdf

Handley, S. J., Newstead, S. E., \& Trippas, D. (2011). Logic, beliefs, and instruction: a test of the default interventionist account of belief bias. Journal of Experimental Psychology: Learning, Memory, and Cognition, 37(1), 28. doi: 10.1037/a0021098

Johnson-Laird, P. N. (2005). Mental Models and Thought. In Holyoak, K. J., \& Morrison R. G., The Cambridge Handbook of Thinking and Reasoning, (pp.185-208). New York: Cambridge University Press.

Johnson-Laird, P. N. (2006). How we reason. Oxford: Oxford University Press.

Johnson, E. D., Tubau, E., \& De Neys, W. (2016). The Doubting System 1: Evidence for automatic substitution sensitivity. Acta psychologica, 164, 56-64. doi: 10.1016/j.actpsy.2015.12.008 
Kaplan, H., Hill, K., Lancaster, J., \& Hurtado, A. M. (2000). A theory of human life history evolution: diet, intelligence, and longevity. Evolutionary Anthropology: Issues, News, and Reviews, 9(4), 156-185. doi: 10.1002/1520-6505(2000)9:4<156::AID-EVAN5>3.0.CO;2-7

Khemlani, S., \& Johnson-Laird, P. N. (2012). Theories of the Syllogism: A Meta-Analysis. Psychological Bulletin, 138(3), 427-57. doi: 10.1037/a0026841

Kirschner, F., Paas, F., \& Kirschner, P. A. (2011). Task complexity as a driver for collaborative learning efficiency: The collective working-memory effect. Applied Cognitive Psychology, 25(4), 615-624. doi: 10.1002/acp.1730

Markovits, H. (1986). Familiarity effects in conditional reasoning. Journal of Educational Psychology, 78(6), 492-494.

Markovits, H., \& Lortie-Forgues, H. (2011). Conditional reasoning with false premises facilitates the transition between familiar and abstract reasoning. Child Development, 82(2), 646-660. doi: 10.1111/j.1467-8624.2010.01526.x

Miyake, A., Friedman, N. P., Rettinger, D. A., Shah, P., \& Hegarty, M. (2001). How are visuospatial working memory, executive functioning, and spatial abilities related? A latent-variable analysis. Journal of experimental psychology: General, 130(4), 621. doi: 10.1037/0096-3445.130.4.621

Morsanyi, K., Devine, A., Nobes, A., \& Szücs, D. (2013). The link between logic, mathematics and imagination: Evidence from children with developmental dyscalculia and mathematically gifted children. Developmental science, 16(4), 542-553. doi: 10.1111/desc.12048

Morsanyi, K., \& Handley, S. J. (2008). How smart do you need to be to get it wrong? The role of cognitive capacity in the development of heuristic-based judgment. Journal of Experimental Child Psychology, 99(1), 18-36. doi: 10.1016/j.jecp.2007.08.003

Morsanyi, K., \& Handley, S. J. (2012). Logic feels so good-I like it! Evidence for intuitive detection of logicality in syllogistic reasoning. Journal of Experimental Psychology: Learning, Memory, and Cognition, 38(3), 596. doi: 10.1037/a0026099

Newstead, S. E., Handley, S. J., Harley, C., Wright, H., \& Farrelly, D. (2004). Individual differences in deductive reasoning. Quarterly Journal of Experimental Psychology Section A, 57(1), 33-60. doi: 10.1080/02724980343000116

Paas, F., \& Ayres, P. (2014). Cognitive load theory: A broader view on the role of memory in learning and education. Educational Psychology Review, 26(2), 191-195. doi: 10.1007/s10648-014-9263-5

Paas, F., Renkl, A., \& Sweller, J. (2003). Cognitive load theory and instructional design: Recent developments. Educational psychologist, 38(1), 1-4. doi: 10.1207/S15326985EP3801_1 
Paas, F., \& Sweller, J. (2012). An evolutionary upgrade of cognitive load theory: Using the human motor system and collaboration to support the learning of complex cognitive tasks. Educational Psychology Review, 24(1), 27-45. doi: 10.1007/s10648-011-9179-2

Ping, R., \& Goldin-Meadow, S. (2010). Gesturing saves cognitive resources when talking about nonpresent objects. Cognitive Science, 34(4), 602-619. doi: 10.1111/j.1551-6709.2010.01102.x

Richerson, P. J., \& Boyd, R. (2005). Not by genes alone: How culture transformed human evolution. Chicago: University of Chicago Press.

Stanovich, K. E., \& West, R. F. (2000). Individual differences in reasoning: Implications for the rationality debate? Behavioral and brain sciences, 23(05), 701-717.

Stanovich, K. E., West, R. F., \& Toplak, M. E. (2011). The complexity of developmental predictions from dual process models. Developmental Review, 31(2), 103-118. doi: 10.1016/j.dr.2011.07.003

Sweller, J. (2015). In academe, what is learned, and how is it learned?. Current Directions in Psychological Science, 24(3), 190-194. doi: 10.1177/0963721415569570

Sweller, J., Ayres, P., \& Kalyuga, S. (2011). Cognitive load theory (vol. 1). New York: Springer.

Sweller, J., \& Sweller, S. (2006). Natural information processing systems. Evolutionary Psychology, 4(1). doi: 10.1177/147470490600400135

Sweller, J. (2008). Instructional implications of David C. Geary's evolutionary educational psychology. Educational Psychologist, 43(4), 214-216. doi: 10.1080/00461520802392208

Trémolière, B., Gagnon, M. È., \& Blanchette, I. (2017). Cognitive Load Mediates the Effect of Emotion on Analytical Thinking. Experimental Psychology. doi: 10.1027/1618-3169/a000333

Tricot, A., \& Sweller, J. (2014). Domain-specific knowledge and why teaching generic skills does not work. Educational psychology review, 26(2), 265-283. doi: 10.1007/s10648-013-9243-1

Van Gog, T., Paas, F., Marcus, N., Ayres, P., \& Sweller, J. (2009). The mirror neuron system and observational learning: Implications for the effectiveness of dynamic visualizations. Educational Psychology Review, 21(1), 21-30. doi: 10.1007/s10648-008-9094-3

Youssef, A., Ayres, P., \& Sweller, J. (2012). Using general problem-solving strategies to generate ideas in order to solve geography problems. Applied Cognitive Psychology, 26(6), 872-877. doi: 10.1002/acp. 2888 


\section{Tables}

Table 1: Results from linear mixed-effects models regarding the influence of the two knowledge types on the dependent variables in Experiment 1. Analysis are described with means (M) and standard deviation (SD).

\begin{tabular}{lcccccc}
\hline & \multicolumn{2}{c}{ Primary Knowledge } & \multicolumn{2}{l}{ Secondary Knowledge } & $\chi^{2}(1)$ & $p$ \\
& M & SD & M & SD & & \\
& & & & & & \\
\hline Performance & 67.79 & 19.99 & 61.04 & 21.05 & 527.56 & $<.001$ \\
Enjoy answering questions & 52.52 & 28.02 & 43.22 & 30.03 & 262.00 & $<.001$ \\
Want to find the correct answers & 63.90 & 27.60 & 55.73 & 29.98 & 210.74 & $<.001$ \\
Confidence & 59.96 & 29.55 & 49.96 & 31.06 & 253.26 & $<.001$ \\
Perceived cognitive load & 39.89 & 22.35 & 48.11 & 23.81 & 288.55 & $<.001$ \\
Speed (pb/min) & 4.22 & 6.80 & 3.49 & 5.25 & 13.25 & $<.001$ \\
\hline
\end{tabular}

Table 2: Results from linear mixed-effects models regarding the influence of the two knowledge types on the dependent variables in Experiment 2. Analysis are described with means (M) and standard deviation (SD).

\begin{tabular}{lcccccc}
\hline & Primary Knowledge & Secondary Knowledge & $\chi^{2}(1)$ & $p$ \\
& M & SD & M & SD & & \\
\hline Performance & 56.52 & 17.38 & 47.52 & 14.96 & 661.07 & $<.001$ \\
Enjoy answering questions & 50.53 & 34.20 & 39.03 & 32.62 & 250.53 & $<.001$ \\
Want to find the correct answers & 65.92 & 32.57 & 60.73 & 33.24 & 59.90 & $<.001$ \\
Confidence & 57.39 & 33.20 & 49.71 & 33.71 & 93.40 & $<.001$ \\
Perceived cognitive load & 42.49 & 27.11 & 48.47 & 26.52 & 98.12 & $<.001$ \\
\hline
\end{tabular}




\section{Figures legends}

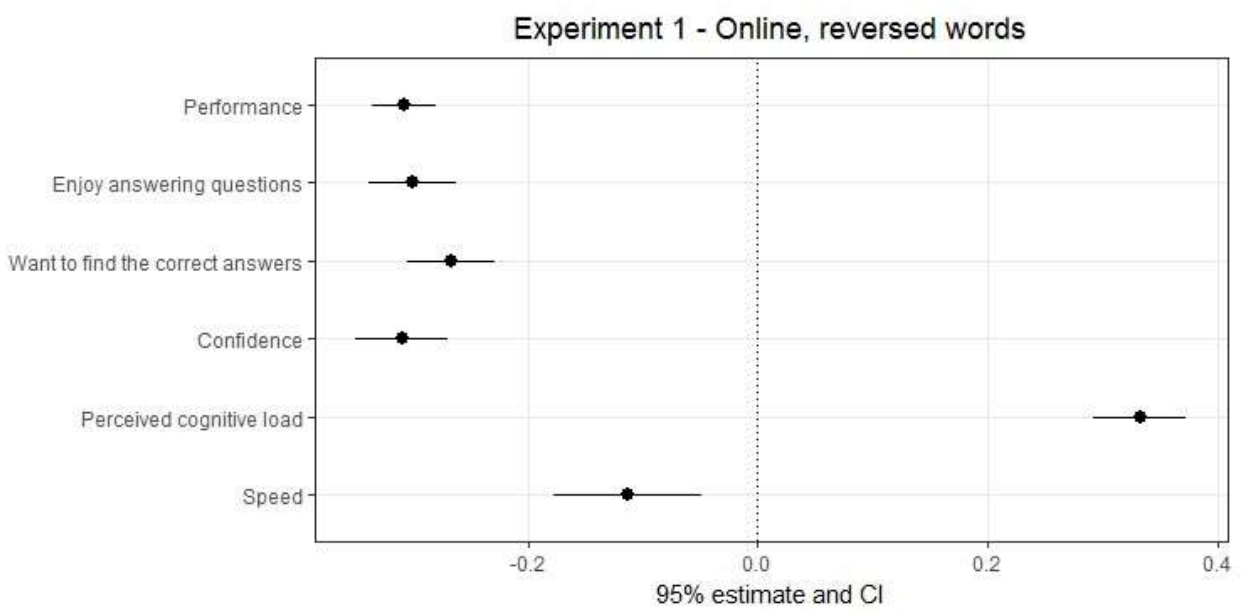

Figure 1: Results from linear mixed-effects models regarding the influence of the two knowledge types on the dependent variables in Experiment 1 (the reference modality is "primary knowledge").

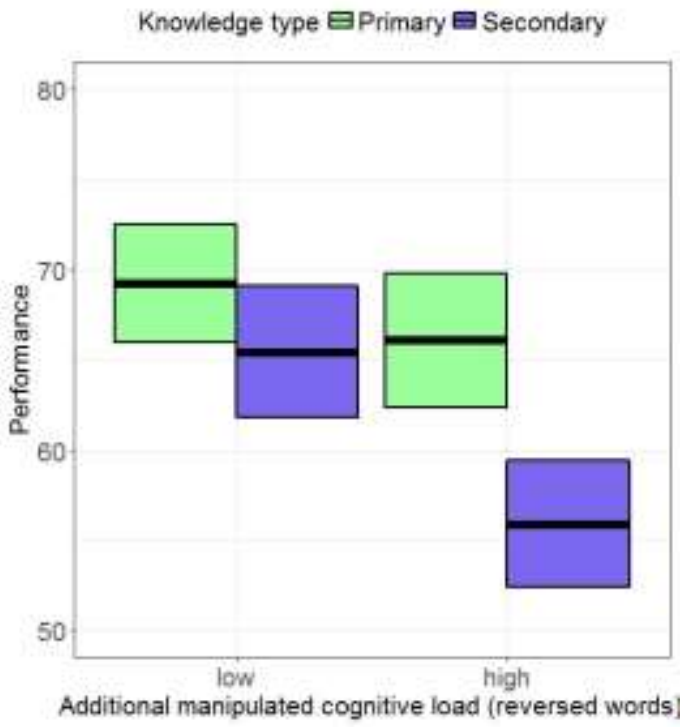

Figure 2: Influence of the additional manipulated cognitive load modality (reversed words) on the two knowledge types regarding the performance $(\min =0, \max =100)$ in Experiment 1 (boxplots represent the mean and $95 \%$ of the confidence interval). 
a)

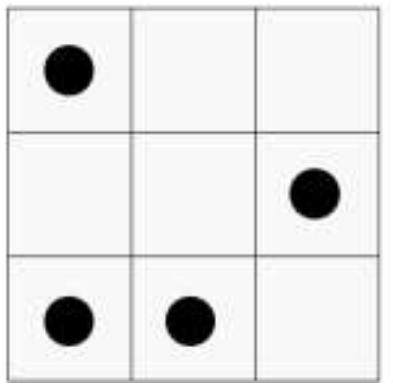

b)

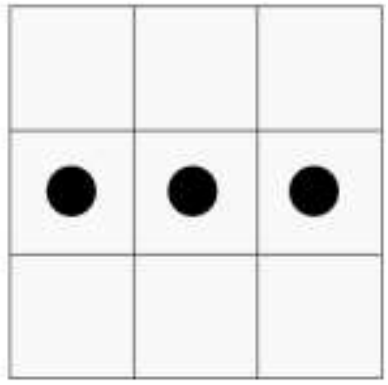

Figure 3: Examples of Dot Memory Task patterns regarding a) the high cognitive load modality and b) the low cognitive load modality.

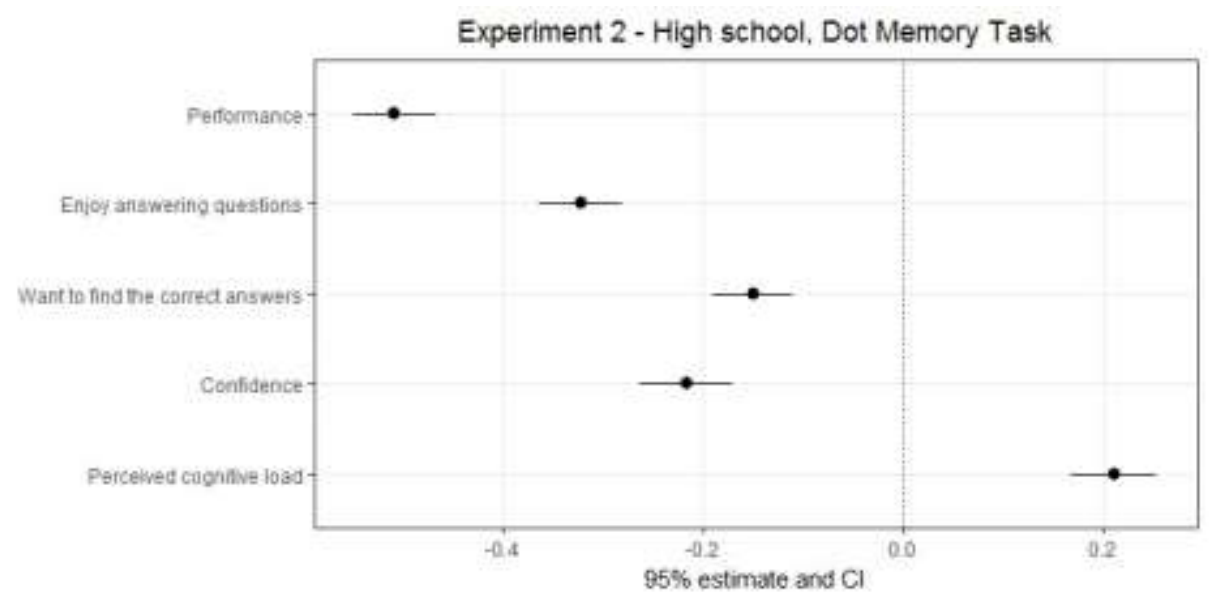

Figure 4: Results from linear mixed-effects models regarding the influence of the two knowledge types on the dependent variables in Experiment 2 (the reference modality is "primary knowledge"). 


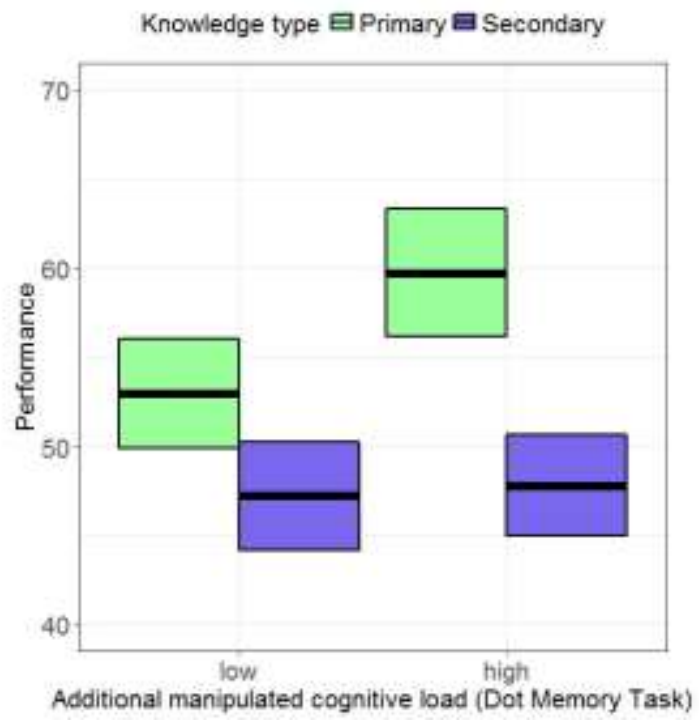

Figure 5: Influence of the additional manipulated cognitive load modality (Dot Memory Task) on the two knowledge types regarding the performance $(\min =0, \max =100)$ in Experiment 2 (boxplots represent the mean and $95 \%$ of the confidence interval). 
a)

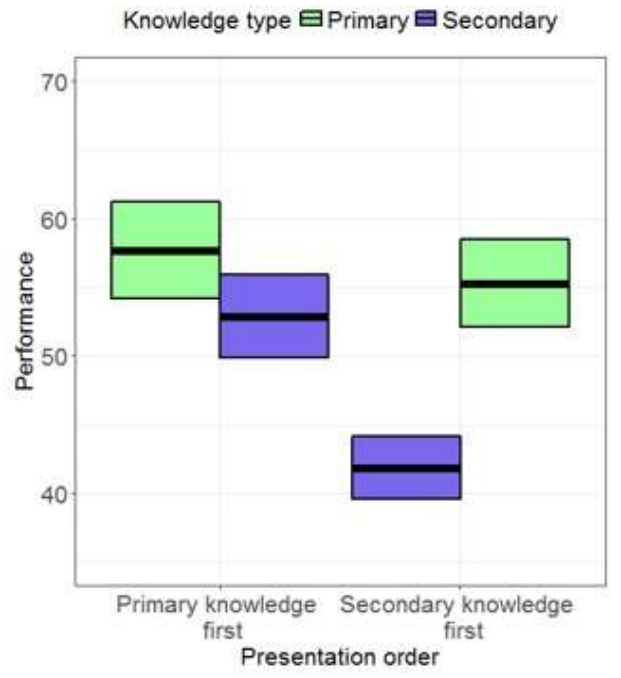

b)

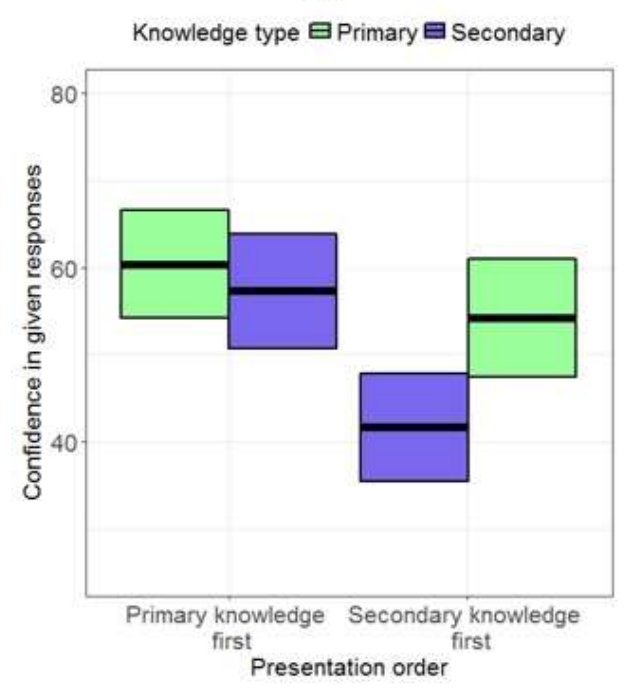

c)

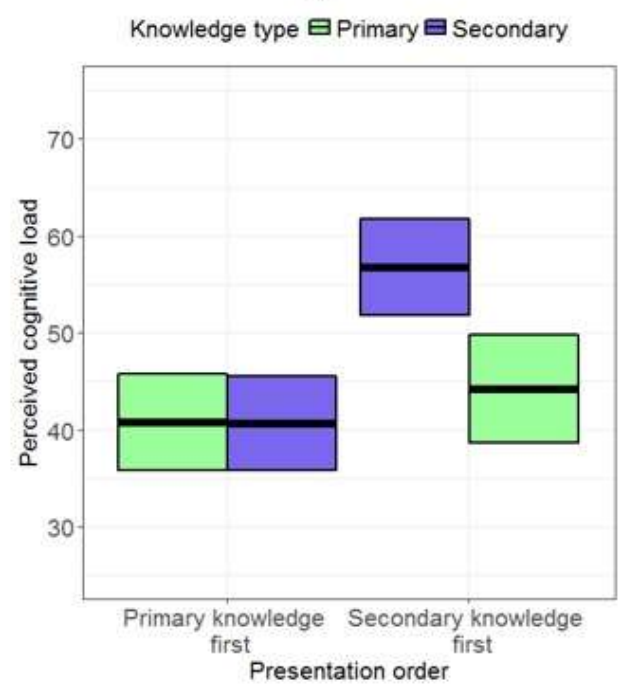

Figure 6: Influence of the presentation order regarding the two knowledge types on a) the performance, $b$ ) the confidence in given responses and c) the perceived cognitive load ( $\min =0$, $\max =100$ ) in Experiment 2 (boxplots represent the mean and $95 \%$ of the confidence interval). 